\title{
GESTÃO ESTRATÉGICA DE SISTEMAS DE EDUCAÇÃO A DISTÂNCIA NO BRASIL E EM PORTUGAL: A PROPÓSITO DA FLEXIBILIDADE EDUCACIONAL
}

\author{
DANIEL Mill
}

\begin{abstract}
RESUMO: O texto apresenta reflexóes sobre os princípios da flexibilidade educacional e sua repercussão na qualidade de propostas de ensino-aprendizagem da Educação a Distância (EaD). No trabalho, o Grupo Horizonte analisa o espaço, o tempo e a organizaçáo curricular como elementos fundantes da flexibilidade. Sendo qualiquantitativa, a pesquisa usou entrevistas semiestruturadas e questionários virtuais na coleta de dados. Estruturou-se uma matriz comparativa das experiências de $\mathrm{EaD}$ portuguesas e brasileiras para buscar estratégias de flexibilidade pedagógica bem-sucedidas em modelos lusos que enriquecessem a $\mathrm{EaD}$ brasileira. Observamos que experiências de $\mathrm{EaD}$ portuguesas e brasileiras ainda buscam maior maleabilidade pedagógica. Anseiam por mais conhecimentos sobre a flexibilidade pedagógica: onde (espaço), quando (tempo) e como (organização curricular) ocorre o ensino-aprendizagem na cibercultura.
\end{abstract}

Palavras-chave: Flexibilidade educacional; Espaço; Tempo; Currículo; Tecnologias digitais.

\section{STRATEGIC MANAGEMENT OF DISTANCE EDUCATION SYSTEMS IN BRAZIL AND PORTUGAL: ABOUT THE EDUCATIONAL FLEXIBILITY}

ABSTRACT: This paper presents reflections on the principles of educational flexibility and their impact on the quality of teachinglearning proposals for Distance Education (DE). In this research, the Horizon Group (Grupo Horizonte - Research and Study Group on Innovation in Education, Technologies and Languages) analyzes the space, time and curriculum organization, conceived as the founding elements of flexibility. Being qualiquantitative, the research adopted semi-structured interviews and virtual questionnaires to collect data. A comparative matrix was structured to analyze DE experiences in Brazil and Portugal in order to identify successful flexibility strategies in Portugal that could

\footnotetext{
* Universidade Federal de São Carlos, Programa de Pós-Graduação em Educação, São Carlos, SP., Brasil. E-mail de contato: mill.ufscar@gmail.com.
} 
enrich Brazilian DE. We observed that the Portuguese and Brazilian DE experiences are still seeking greater malleability in the pedagogical model and both are searching for more knowledge on pedagogical flexibility: where (space), when (time) and how (curricular organization) teaching and learning takes place in cyberculture.

Keywords: Educational flexibility; Space; Time; Curriculum; Digital technologies.

\section{GESTION STRATÉGIQUE DE SYSTÈMES D'ENSEIGNEMENT À DISTANCE AU BRÉSIl ET AU PORTUGal: SUR LA FLEXIBILITÉ PÉDAGOGIQUE}

RÉSUMÉ: Cet article présente une réflexion sur les principes de la flexibilité pédagogique et son impact sur la qualité de l'enseignement à distance (EaD). Dans ce travail, le Groupe Horizon analyse l'espace, le temps et l'organisation curriculaire comme des éléments fondamentaux de la flexibilité. Pour être quali-quantitative, la recherche a adopté des entretiens semi-structurés et des questionnaires pour recueillir des données. Une matrice a été créé pour comparer les expériences portugaises et brésiliennes d'enseignement à distance. Cette analyse a identifié des stratégies efficaces de flexibilité dans les modèles pédagogiques portugais qui enrichissent les expériences brésiliennes. Nous avons observé que les expériences portugaises et brésiliennes sont toujours à la recherche d'une plus grande souplesse dans le modèle pédagogique. Ils cherchent une meilleure connaissance sur la flexibilité pédagogique: où (espace), quand (temps) et comment (organisation curriculaire) l'enseignement et l'apprentissage se déroulent dans la cyberculture.

Mots-clés: Flexibilité pédagogique; L'espace; Le temps; L'organisation curriculaire; Les technologies numériques.

\section{Considerações iniciais}

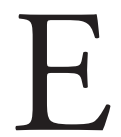

spaço , tempo e organização curricular são categorias centrais para pensar e fazer educação. Extremamente complexos de modo particular e, em conjunto, esses três elementos são pilares essenciais de praticamente todos os modelos pedagógicos. Ao elaborar uma proposta de curso, por exemplo, há sempre a preocupação com uma configuração de tempos, espaços e matriz curricular mais adequada ao atendimento das condições de cada estudante. Em outras palavras, a temática flexibilidade está sempre em foco quando estruturamos um projeto de curso, mas nem sempre recebe a devida atenção na concepção pedagógica. Como já indicamos em outros estudos, são escassos os estudos e 
pesquisas sobre a flexibilidade pedagógica. Nesse sentido, propomos neste texto analisar possíveis formas de flexibilização dos espaços e tempos educacionais e da organização curricular, adotadas nos modelos de $\mathrm{EaD}$ portugueses e brasileiros. $\mathrm{O}$ texto apresenta resultados de uma investigação que buscou, direta ou indiretamente, levantar estratégias para melhor atendimento às condiçōes de horário e lugar de estudos dos alunos ${ }^{1}$.

A flexibilização pedagógica exerce papel preponderante na democratização do conhecimento, no respeito às diferenças de condiçôes de vida do educando, na equidade da formação, na personalização da formação, na adaptação da formação ao contexto de vida do estudante e, por conseguinte, na otimizaçáo dos recursos públicos dedicados à educação. Além disso, consideramos que a modalidade de $\mathrm{EaD}$ pode ser configurada com espaço-tempo e currículo mais flexíveis, de modo a atender mais adequadamente às condições de vida dos alunos, seja em termos de organização dos horários e lugares de estudo ou da articulação desses com o trabalho e a convivência social (amigos, família etc.). Sendo a flexibilidade educacional essencial para configurar melhores propostas de formação, este artigo representa uma contribuição para um adequado entendimento da temática e para a proposição de formas de $\mathrm{EaD}$ mais ricas e flexíveis. Todavia, não temos qualquer pretensão de esgotar a temática neste texto.

\section{Figura 1}

Proposta de elementos para problematização/reflexóes sobre a flexibilização pedagógica

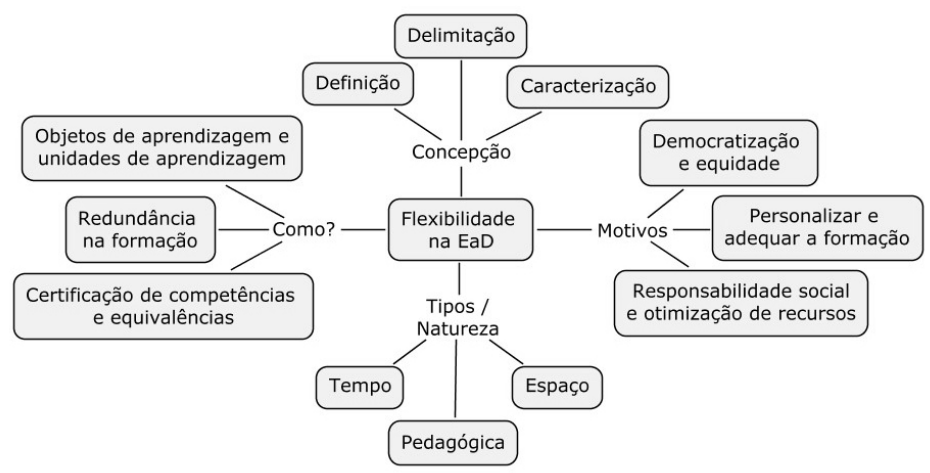

Para fazer esta reflexão sobre a flexibilidade pedagógica, analisaremos o tema com base no diagrama de elementos da Figura 1. Começando pela definição de flexibilidade, passando pela motivação do estudo e tipificação/caracterização da temática e, ao final, indicação de formas e açóes que norteiam algumas estratégias de flexibilização espaçotemporal e curricular. 


\section{Contextualizando a discussão: a educação virtual como flexibilização dos espaços, tempos e currículo na atualidade}

As tecnologias digitais de informação e comunicação (TDIC) afetaram quase todas as áreas do conhecimento e reorganizaram praticamente todos os espaços e tempos de convivência ou exploração humana. Como afirmou Harvey (2009), no alicerce dessas transformações está o redimensionamento dos espaços e tempos tradicionalmente estabelecidos em períodos anteriores à cibercultura. (LEVY, 1999) Essas tecnologias digitais criaram condiçóes favoráveis para experiências diferenciadas e novas noçôes em relação ao lugarlespaço e ao horáriol momento/tempo de socialização, com implicações plurais, de natureza cultural, social, política, ambiental, geográfica, artística, trabalhista etc.

Do mesmo modo, a educação tem passado por transformaçôes decorrentes do atual estágio de desenvolvimento tecnológico. Quando traçam as bases para a compreensão dos lugares e momentos em geral, Elias (1998) e Frago e Escolano (2001) contribuem também para o entendimento dessa influência das TDIC sobre o ensino-aprendizagem. A sala de aula pode ser entendida apenas como um lugar percebido, construído socialmente e simbolicamente. Espaços com significados e representaçóes de espaços, pois a percepção é um processo cultural. (FRAGO; ESCOLANO, 2001) A noção de tempo e a relação que os homens estabelecem com ele variam de acordo com o estágio de desenvolvimento em que se encontram os grupos humanos. (ELIAS, 1998) Ou seja, a experiência do tempo não é necessariamente a mesma para todos os grupos humanos. Essas bases espaçotemporais sugerem uma interpretação não apenas da disposição material dos espaços, como também de sua dimensão simbólica - o valor didático do símbolo constitui um aspecto a mais da dimensão educativa do espaço e do tempo.

Nesse sentido, infere-se que os espaços e tempos de ensino-aprendizagem da educação virtual são apenas uma configuração distinta dos ambientes de aprendizagem tradicionais. Reconfigurados de forma distinta da educação presencial, os novos espaços e tempos adéquam-se às novas necessidades e, ou, ao estágio de desenvolvimento tecnológico. Ou seja, as TDIC promovem a "compressão" espaçotemporal e a "necessidade" de maior flexibilidade nos espaços e tempos sociais, instalando uma cultura "do acesso" e "do aqui-agora", que tem suas bases na flexibilidade ou fluidez dos espaço-tempos da cibercultura. O desejo de novos horários e locais de convivência familiar/social, trabalho, lazer, estudos e demais responsabilidades leva os sujeitos a valorizarem os redimensionamentos promovidos pelas TDIC.

O desenvolvimento das tecnologias de informação e comunicação permite cada vez mais o rompimento de limitaçóes temporais e espaciais. Muitos são aqueles que, graças a esta flexibilidade de 
nossa relação com o tempo e com o espaço, sonham com uma sociedade organizada com uma nova distribuição dos horários de trabalho, deixando a parte bela da vida ao lazer e à família. (ROSSEL et al., 1998, p.267)

No campo educacional, de alguma forma, essa valorização (demasiada, por sinal) do rompimento das barreiras espaçotemporais favorece, por exemplo, a recente expansão e valorização da $\mathrm{EaD}$. As novas configuraçóes dos modelos de $\mathrm{EaD}$ (ensino a distância, aprendizagem aberta, educação virtual, educaçáo on-line, b-learning, e-learning, m-learning, u-learning etc. $)^{2}$ são formas distintas de organização dos tempos, espaços e matriz curricular. Por princípio, a modalidade de EaD busca flexibilizar o modelo tradicional de ensino-aprendizagem para democratizar o conhecimento, por meio de novas possibilidades de formaçáo. As TDIC potencializaram as formas de efetivar esse objetivo, implícito inclusive na definição de Educação a Distância, como veremos adiante.

A flexibilização da formação (curricular, em particular) tem sido motivada pela necessidade de adequar o processo educacional às dinâmicas do conhecimento, da ciência e da prática profissional. Todavia, na educação presencial isso sempre foi (e continua sendo) um imenso desafio para gestores e educadores, pois essa flexibilidade pressupóe liberdade e mobilidade estudantil em termos de espaço, tempo e organização curricular. Essa maleabilidade não é facilmente implementável com as possibilidades espaçotemporais ou curriculares da educação tradicional. Pelo uso intensivo das tecnologias digitais, a flexibilidade educacional tem se mostrado mais tangível, o que torna a educaçáo virtual um tipo de $\mathrm{EaD}$ mais promissor em termos de flexibilidade e adaptação às condições de vida do estudante. Nesse sentido, este texto analisa a flexibilidade no contexto da $\mathrm{EaD}$, com foco na virtualização dos processos de ensino-aprendizagem pelas TDIC.

\section{Concepção de flexibilidade educacional: breve caracterização e definição}

Como tratar da flexibilidade no âmbito educacional? É igualmente possível tratar de flexibilidade na educação ou em outras áreas do conhecimento? Qual a importância /necessidade/vantagens da flexibilidade pedagógica, entendida aqui como maleabilidade temporal, espacial e curricular?

De partida, a própria definição de Educação a Distância considera essas questôes espaçotemporais. Apesar do equívoco ao considerar educação e aprendizagem como sinônimos, a definiçáo de Moore e Kearskey (2008) elucida bem a relação direta entre a $\mathrm{EaD}$ e o esforço para romper com os espaços/lugares e tempos/horários tradicionais. 
Educação a distância é o aprendizado planejado que ocorre normalmente em um lugar diferente do local do ensino, exigindo técnicas especiais de criação do curso e de instrução, comunicação por meio de várias tecnologias e disposiçôes organizacionais e administrativas especiais. (MOORE; KEARSLEY, 2008, p.2)

Observa-se que o uso intensivo de tecnologias digitais e a separação física (espaçotemporal) entre aluno e professor são prerrogativas básicas da $\mathrm{EaD}$.

No texto Flexible education, Tubella et al. (2011) concluem que a flexibilidade é uma característica muito valorizada pelos estudantes mais jovens, que fomentam também a criação de formas alternativas ou diferenciadas de aprendizagem e compartilhamento do conhecimento. $\mathrm{O}$ anseio por ambientes de aprendizagem com arquiteturas mais flexíveis, permeados por maiores possibilidades de colaboração e participação efetiva, leva os jovens estudantes a incorporarem tecnologias digitais no seu planejamento e organização dos estudos. Imersas num contexto cibercultural, caracterizado como um mundo em rede em que todos e tudo estão conectados, as novas geraçôes valorizam mais o conhecimento acumulado, criado e compartilhado do que aqueles conhecimentos possuídos e gerenciados como instrumento de poder e diferenciação. (TUBELLA et al., 2011, p.10) Veremos adiante que a flexibilidade, em suas diferentes formas, tem papel de destaque nesse anseio por formação mais colaborativa e personalizada.

Assim, o ponto de partida dessa discussão parece estar no esclarecimento da noção de flexibilidade que está sendo adotada neste texto: o que é flexibilidade? Sobre que tipo de flexibilidade este texto traz reflexôes? Sabe-se que existem diversas noções de flexibilidade e que, mesmo no âmbito educacional, ela pode tomar diversas facetas. Como primeiro passo, trataremos neste texto de uma perspectiva particular, como se segue.

De modo mais amplo, a definição de flexibilidade não guarda segredos. Há pouco a elucidar, pois é um termo comum, simples e já dicionarizado há bastante tempo. Entre os significados do termo, o dicionário Houaiss (2001) indica que flexibilidade é a qualidade daquilo que é flexível - que, por sua vez, significa aquilo que se dobra ou verga facilmente sem se quebrar, que se acomoda suavemente ou sem resistência. O termo vem do latim flexibilis (dobrável), derivado de flectere (dobrar). Assim, flexibilidade educacional pode ser entendida pelas possibilidades de (re)organização da educação, em função de diversos interesses ou necessidades. A capacidade de adaptação da proposta de formação aos perfis e interesses dos estudantes é, portanto, o centro da noçáo de flexibilidade educacional que está sob nosso olhar neste texto.

Existem algumas formas mais antigas de tornar uma proposta pedagógica mais flexibilizada, tais como a organização curricular através de módulos ou a descentralização dos espaços pela parceria com polos. Independente das for- 
mas possíveis, neste texto interessa o tipo particular de flexibilidade educacional marcado pela maleabilidade espaçotemporal e curricular. Em especial, queremos discutir as possibilidades dessa flexibilidade no âmbito da EaD, que, embora possua uma estrutura semelhante à da educação presencial, possibilita formas de organização pedagógica mais dinâmicas e maleáveis do que a educação tradicional. Aliás, pode-se dizer que a principal diferença entre as duas modalidades centra-se nessa maior ou menor flexibilidade dos lugares, horários e formas de estudos. Enfim, a flexibilidade educacional pode ser entendida em três perspectivas complementares e essenciais: foco nos espaços, nos tempos e na organização curricular (Figura 2).

\section{Figura 2}

Perspectivas de análise da flexibilidade na educação: espaços, tempos e organização curricular.

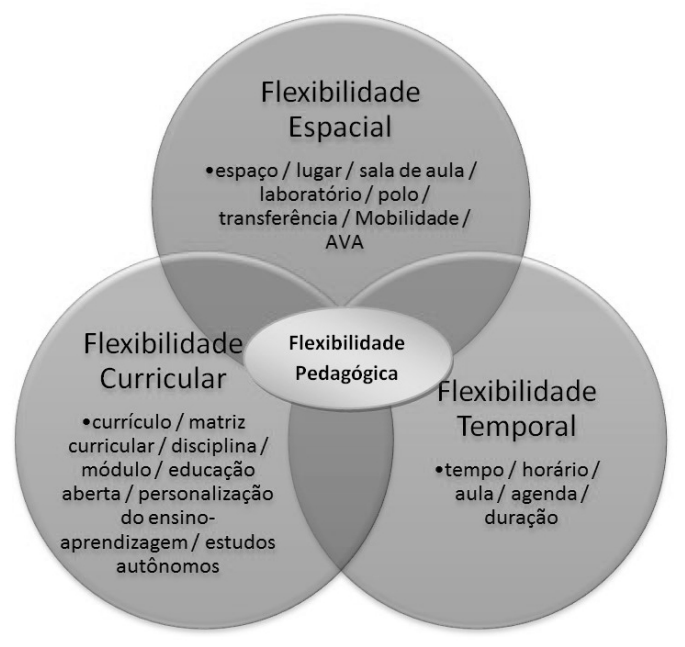

Quando tratamos da flexibilidade espacial na educação, estamos interessados, entre outros elementos, nas possibilidades de mobilidade geográfica, limitações físicas e de deslocamento dos estudantes, organização de ambientes pedagógicos (laboratórios, bibliotecas ou salas de aula, por exemplo). As noçóes de lugar de ensino-aprendizagem são colocadas em jogo quando consideramos o como e o porquê flexibilizar os espaços escolares ou acadêmicos da educação presencial, historicamente constituídos. Como afirmou Mill (2012), a educação está relacionada com tempos e espaços numa firme amálgama e a história da educação nos indica que:

[...] as melhores estratégias de ensino-aprendizagem buscaram organizar o tempo em blocos diários, semanais, mensais ou 
anuais, em fases da vida (infância, juventude, adultos etc.), em etapas ou níveis de conhecimento (fundamental, médio, superior etc.) e o espaço em prédios e outras construçóes (como escolas, universidades etc.), distribuídos em salas de aula, biblioteca, laboratórios e outros ordenamentos espaciais. (MILL, 2012, p. 106)

Pensar na flexibilidade dos tempos educacionais implica considerar horários e momentos de convivência/relaçóes entre educadores-educandos-educandos-conteúdos-conteúdos-educadores, nas possibilidades de personalização dos estudos, na (as) sincronicidade dos estudos, nos aspectos logísticos e fluxos de materiais e pessoas, na organização temporal dos ambientes pedagógicos (aulas, intervalos, horários de disciplinas, atividades físicas, semestralidade, séries, por exemplo). As noçóes de momentos de ensino-aprendizagem são colocadas em jogo quando consideramos o quando e o porquê flexibilizar os tempos escolares ou acadêmicos da educação presencial, historicamente constituídos.

Por fim, a noção de flexibilidade educacional abarca também formas de organização curricular plurais, que tem recebido atenção em discussóes sobre ensino superior. Por exemplo, o Fórum Nacional de Pró-Reitores de Graduação das Universidades Brasileiras (FORGRAD, 2003) apresentou, há 10 anos, um documento sobre concepçóes e implementação da flexibilidade curricular.

O entendimento tomado no documento é que a flexibilização curricular é algo que se impóe nas reformas curriculares dos cursos de graduação face às exigências das rápidas transformaçôes socioeconômicas, geopolíticas, culturais e tecnológicas que vêm ocorrendo na sociedade, com seus desdobramentos gerais e particulares na educação, em especial, no ensino superior. (FORGRAD, 2003)

Assim, uma matriz curricular pode ser organizada de modo mais rígido ou mais maleável; pode contemplar disciplinas, módulos, unidades de aprendizagem ou outras subdivisóes do conhecimento para fins didáticos. Pensar a flexibilidade educacional exige, portanto, refletir sobre a flexibilidade curricular, que pode ser entendida como uma forma de organização do conhecimento, cuja matriz curricular não é rígida. A formação é, portanto, entendida como um percurso com possibilidades alternativas de trajetórias. A flexibilidade curricular busca a promoção de maior liberdade ao estudante e educadores para definição e desenvolvimento das atividades da formação, de modo mais maleável e adequado a sujeitos plurais, imersos em contextos dinâmicos, complexos e em constante transformação. 
Vale destacar, ainda, que apesar das discussóes já avançadas sobre as diferentes teorias do currículo e dos senóes indicados quanto a esta ou aquela vertente de análise, estamos entendendo aqui currículo numa perspectiva mais tradicional. No intuito de resumir as grandes categorias de teorias do currículo, Silva (2004) levanta pelo menos três grupos de conceitos empregados pelas teorias: teorias tradicionais, teorias críticas e teorias pós-críticas. Os conceitos mais recorrentes apontados pelo autor nas teorias mais tradicionais de currículo são: ensino, aprendizagem, avaliação, metodologia, didática, organização, planejamento, eficiência e objetivos. (SILVA, 2004, p. 17) Apesar da riqueza e da profundidade de análise que as outras duas categorias de teoria possibilitam, em relação à tradicional, esta nos permite demonstrar didaticamente melhor o objeto de análise deste texto: a flexibilidade educacional.

De todo modo, consideramos impossível analisar aspectos educacionais da cibercultura sem claro entendimento da amplitude e abrangência do currículo. $\mathrm{O}$ contexto propiciado pelas tecnologias digitais requer a configuração de uma noção de currículo capaz de atender a sujeitos diferentes e situados em contextos dinâmicos, em constante transformação. Como afirma Silva (2008),

Um currículo, nesse [atual] contexto de transformação, exige novas competências e novas habilidades desenvolvidas em processo contínuo e significativo. Exige administração de processos com flexibilidade para atender a diferentes pessoas e situaçóes e às mudanças permanentes que caracterizam o mundo da sociedade da informação. (SILVA, 2008, p.126)

Para Silva (2008) é no seio da complexidade dos fenômenos sociais que o currículo deve ser desenvolvido e, sabemos, as teorias tradicionais do currículo podem não dar conta da diversidade de fenômenos tangentes ao processo educacional na atualidade. No âmbito da $\mathrm{EaD}$, estas questóes póem em pauta a noção de currículo sob análise: não sendo neutras, as tecnologias digitais de informação e comunicação que fazem a mediação dos processos na $\mathrm{EaD}$, influenciam a estruturação do currículo segundo os modos de produção e interação que lhes são inerentes. Nessa situação, as mudanças podem ir além do tempo, do espaço e da organização curricular, pois forma e conteúdo se inter-relacionam e se transformam mutuamente pela forma como a EaD se organiza em decorrência das TDIC. Enfim, nem a $\mathrm{EaD}$ e nem as tecnologias digitais são neutras e isso requer cuidados na análise do currículo. Mesmo assim, apesar de possíveis limitaçóes quanto aos elementos que compóem o currículo, para além da organização curricular em sentido estrito, didaticamente consideramos adequado a adoção da noção tradicional do currículo para refletir sobre flexibilidade na organização pedagógica. Isto é, a maleabilidade curricular de que tratamos nesta discussão refere-se mais aos aspectos contemplados pela teoria tradicional do currículo. É pela flexibilidade 
da matriz curricular que uma formação pode ser ou não mais adequada ao perfil e condiçóes de vida dos sujeitos aprendentes, em respeito aos seus ritmos e estilos de aprendizagem e aos seus horários e locais de estudos, trabalho, lazer, convívio familiar e outras responsabilidades particulares.

Por isso, sabendo do papel da organização curricular na maior rigidez ou dinamicidade da formação, consideramos importante lançar luz na capacidade ou limitação da $\mathrm{EaD}$ em adotar uma proposta educacional mais flexível, adequada a sujeitos plurais, imersos em contextos dinâmicos, complexos e em constante transformação.

Como veremos, a flexibilidade pedagógica na $\mathrm{EaD}$ está diretamente relacionada às potencialidades dessa modalidade atender, de modo diverso e múltiplo, a estudantes situados em lugares distantes dos grandes centros de formação acadêmica e impossibilitados de frequentar as aulas em momentos definidos pela academia. Ou seja, flexibilidade pedagógica representa grandes desafios aos educadores para pensar propostas de ensino-aprendizagem com momentos e lugares mais adequados aos estudantes, que terão maior liberdade para realizar as atividades em termos de quando, como e onde estudar. Na prática, o desafio está na dificuldade de efetivar essa flexibilidade, de modo transversal ao espaço, tempo e currículo, acionando os conceitos acima indicados com base em Silva (2004); quais sejam: ensino, aprendizagem, avaliação, metodologia, didática, organização, planejamento, eficiência e objetivos.

Como forma de verificação da efetividade da flexibilidade pedagógica no âmbito da $\mathrm{EaD}$, realizamos uma investigaçáo em experiências brasileiras e portuguesas. A pesquisa teve o propósito de melhor compreender a flexibilidade pedagógica na $\mathrm{EaD}$ nas experiências brasileiras a partir de elementos identificados em experiências portuguesas. Assim, caracterizamos os modelos de $\mathrm{EaD}$ mais comuns daquele país para, comparativamente, identificar elementos que facilitem a compreensão da flexibilidade pedagógica no ensino-aprendizagem virtual típico das condições brasileiras. Nas próximas seçôes, apresentamos sinteticamente a investigação, trazendo alguns dados e uma breve análise sobre flexibilidade educacional na EaD.

\section{Coisas de cá e de além-mar: conhecendo a flexibilidade em experiências na EaD portuguesas e brasileiras}

Observando as várias iniciativas de $\mathrm{EaD}$ em Portugal, identificamos três instituiçôes públicas representativas para caracterizar a modalidade naquele país. Neste trabalho, as instituiçóes de ensino analisadas são denominadas como IE1, 
IE2 e IE3, sendo as duas primeiras instituições de nível superior e a terceira (IE3) de nível médio. Essas instituições se destacam pelos seguintes motivos:

a) IE1: única instituição de nível superior, nacionalmente reconhecida por oferecer cursos exclusivamente pela $\mathrm{EaD}$, além de ser a principal instituição de ensino superior de $\mathrm{EaD}$ do país (com mais de 25 anos de fundação);

b) IE2: principal (senão a única) instituição que oferece educação presencial há anos e, mais recentemente, começou a oferecer cursos de graduação pela $\mathrm{EaD}$. Outras instituiçóes tradicionais de ensino superior estáo se movimentando para incorporar a $\mathrm{EaD}$ como modalidade de formação, mas ainda não ousaram abarcar um curso de graduação totalmente a distância. Elas oferecem, por enquanto, uma ou outra disciplina a distância e, quando muito, oferecem cursos de formação rápida (formação continuada ou especialização, por exemplo); e

c) IE3: única instituição portuguesa reconhecida a oferecer formação em nível médio a distância no país.

Em relação ao Brasil, pela diversidade e pluralidade de experiências em $\mathrm{EaD}$, escolhemos as instituiçóes públicas de ensino superior envolvidas com o Sistema UAB (Universidade Aberta do Brasil) como representativas da formação pública pela $\mathrm{EaD}$ no país. Metodologicamente, essas escolhas se deram pelos seguintes motivos:

a) o padrão comparativo fica mais fácil pela escolha de instituiçóes públicas de ensino nos dois países;

b) embora diversas instituiçôes privadas brasileiras tenham significativas experiências de formação pela $\mathrm{EaD}$ (e, aqui, respeitamos o grande mérito de algumas delas), as instituiçôes de ensino superior públicas brasileiras que se envolveram com EaD ultimamente (na parceria com o Sistema UAB) têm sido as maiores responsáveis pela substancial expansão e mudança de mentalidade em torno da modalidade $\mathrm{EaD}$ no Brasil;

c) a flexibilidade pedagógica como uma das principais dificuldades dos gestores é mais evidente no âmbito das instituições de ensino superior (IES) públicas, seja pelos custos adicionais, pelo conservadorismo típico dos setores públicos ou pelas dificuldades logísticas do processo.

Desta forma, objetivando análises macroscópicas da EaD brasileira, elegemos as três instituiçóes portuguesas para entendimento da $\mathrm{EaD}$ no país lusófono e outras IES brasileiras parceiras do Sistema $\mathrm{UAB}^{3}$. A análise da EaD brasileira foi feita a partir de uma síntese dos aspectos mais recorrentes nas várias experiências; isto é, sistematizamos uma IES padrão com base nas outras.

A coleta de dados em Portugal foi realizada in loco, por meio de entrevistas e observação direta. Para coletar dados no Brasil, foi aplicado um questionário ${ }^{4}$ junto aos gestores de $\mathrm{EaD}$ das instituiçóes brasileiras e, também, foram realizadas 
entrevistas com alguns dos Coordenadores UAB das instituiçóes participantes da pesquisa. Na ocasião eram 88 universidades parceiras do Sistema UAB, sendo que representantes de 46 delas preencheram completamente o formulário e participaram voluntariamente da pesquisa, fornecendo informaçóes sobre os programas de formação pela modalidade de $\mathrm{EaD}$ que coordenam em suas respectivas instituiçóes. A pesquisa foi realizada ao longo de 2011.

\section{Tabela 1}

Síntese da caracterização da flexibilidade pedagógica em instituiçóes portuguesas

\begin{tabular}{|c|c|c|}
\hline \multicolumn{3}{|c|}{ Portugal } \\
\hline IE1 & IE2 & Total \\
\hline $\begin{array}{c}\text { Baixa flexibilidade } \\
\text { curricular e pedagógica: } \\
\text { matrícula é feita } \\
\text { periodicamente em bloco } \\
\text { de disciplinas } \\
\text { obrigatórias e optativas. } \\
\text { A duração minima e } \\
\text { máxima do curso é } \\
\text { predeterminada pela } \\
\text { instituição. } \\
\text { A flexibilidade temporal } \\
\text { e espacial é alta, embora } \\
\text { tenham limitações como } \\
\text { a obrigatoriedade de } \\
\text { deslocamento dos } \\
\text { estudantes à instituição } \\
\text { para realizar atividades } \\
\text { presenciais e com a } \\
\text { duração do curso. } \\
\text { Há dispensa/equivalência } \\
\text { de disciplinas, mas ainda } \\
\text { não há certificação de } \\
\text { competências }\end{array}$ & \begin{tabular}{|} 
Baixa flexibilidade \\
curricular e pedagógica: \\
matrícula é feita \\
periodicamente em bloco \\
de disciplinas de modo \\
quase compulsório. \\
A duração mínima e \\
máxima do curso é \\
predeterminada pela \\
instituição. \\
A flexibilidade temporal e \\
espacial é alta, mas \\
limitada, pois ainda é \\
obrigatório que os \\
estudantes se desloquem à \\
instituição para realizar \\
atividades presenciais e \\
formações complementares \\
(ex: eventuais cursos de \\
férias). \\
Há dispensa/equivalência \\
de disciplinas, mas ainda \\
não há certificação de \\
competências.
\end{tabular} & $\begin{array}{l}\text { Nivel de liberdade curricular e } \\
\text { pedagógica elevada: estudantes } \\
\text { escolhem quantidade e } \\
\text { sequência das disciplinas. } \\
\text { Há flexibilidade temporal plena: } \\
\text { sem restrições de horários ou } \\
\text { duração dos estudos. } \\
\text { Há boa flexibilidade espacial: } \\
\text { sem restrições de lugar de } \\
\text { estudos e o deslocamento para } \\
\text { atividades presenciais é } \\
\text { facilitado pelas negociações. } \\
\text { A flexibilidade é trabalhada a } \\
\text { partir de um contrato de } \\
\text { responsabilização estudantil pela } \\
\text { gestão dos próprios estudos. } \\
\text { Ainda não há certificação de } \\
\text { competências para flexibilizar } \\
\text { plenamente a grade curricular, } \\
\text { mas os gestores têm essa } \\
\text { intensão. } \\
\text { Estudante pode sair e voltar } \\
\text { quando quiser (sem limites } \\
\text { máximos de término do curso). }\end{array}$ \\
\hline
\end{tabular}

Fontes: Autoria própria.

Para estruturar reflexões em torno da categoria de análise flexibilidade pedagógica na EaD, elaboramos uma caracterização mais geral dos sistemas de $\mathrm{EaD}$ públicos brasileiros e portugueses analisados. A partir da síntese da Tabela 1, indicativa dos modelos pedagógicos das três instituiçóes portuguesas, buscamos analisar as condições para maior flexibilidade pedagógica dessas instituiçóes e suas contribuiçôes para entender o fenômeno da flexibilidade na EaD brasileira. 


\section{Tabela 2}

Síntese da caracterização da (baixa) flexibilidade pedagógica na $\mathrm{EaD}$ em condiçóes brasileiras

\begin{tabular}{c}
\hline BE4 (Parceiras UAB) \\
\hline $\begin{array}{c}\text { Apesar de ser bastante limitada, observou-se que há alguma flexibilidade } \\
\text { espaço-temporal; ou seja, há rompimento do lugar/espaço da sala de aula } \\
\text { tradicional e dos horários/tempos de estudo presenciais, mas há ainda a } \\
\text { rigidez das atividades presenciais, do modelo central-polos e da duração dos } \\
\text { cursos. }\end{array}$ \\
Atividades presenciais obrigatórias com horário e lugar predefinido para \\
todos os envolvidos. \\
Sem flexibilidade pedagógica: matrícula em blocos de disciplinas e estudantes \\
(baixa autonomia do estudante). \\
Aceita-se equivalências entre disciplinas cursadas em outra instituição ou \\
modalidade, mas ainda não há certificação de competências. \\
Transferência ou transição entre universidades, cursos ou polos é geralmente \\
limitada, parcial e, às vezes, impossibilitada. \\
Dependência do especialista da disciplina, exigindo reconfiguração ou \\
reelaboração de materiais didáticos a cada semestre.
\end{tabular}

Fontes: Autoria própria.

De modo semelhante, a Tabela 2 apresenta uma síntese da flexibilidade (bem mais limitada) no contexto educacional brasileiro, em um modelo representativo das experiências públicas de $\mathrm{EaD}$ em parceria com a $\mathrm{UAB}$, aqui denominado como IE4. Assim, temos um padrão comparativo para observação das particularidades e contribuiçóes que as experiências portuguesas podem trazer às condições brasileiras.

\section{Flexibilidade em experiências na EaD portuguesas e brasileiras: uma breve análise dos dados da pesquisa}

As informações da Tabela 1 e da Tabela 2 indicam, por si mesmas, alguns elementos dos modelos pedagógicos de $\mathrm{EaD}$ das instituiçóes consideradas na investigação, importantes para a análise da flexibilidade espaçotemporal e curricular. Com base nessas percepçóes, destacamos a seguir alguns pontos afeitos à flexibilização pedagógica: 
- Duração e trancamento do curso: a definição da duração mínima e máxima dos cursos (im)possibilita o estudante adiantar ou retardar a conclusão dos estudos. Isso indica padronização da formação, consequente da maior rigidez curricular e temporal do curso. Apenas a IE3, de ensino médio, dá ao estudante a liberdade de trancamento do curso ou aceleração dos estudos. As IE 1, 2 e 4 não facilitam o adiantamento do curso e a postergação da conclusão é limitada a uma duração máxima do curso.

- Deslocamento obrigatório: apesar de serem cursos realizados a distância, não é facultado ao estudante realizar todas as atividades virtualmente. Muitas atividades ainda são realizadas na sede da instituição ou em polos de apoio presencial. Isso indica limitação da flexibilidade pedagógica em decorrência da rigidez espacial. As IE 1, 2 e 4 exigem presença periódica obrigatória em algum local predefinido.

- Matrícula em blocos de disciplinas predefinidas: normalmente, o aluno é convocado a realizar um conjunto de disciplinas, sem liberdade de escolha da quantidade, tipos ou sequência das disciplinas. Isso é consequência do prazo preestabelecido para conclusão do curso e representa baixa flexibilidade pedagógica, decorrente de uma rigidez da organização curricular. Assim como no item "trancamento de curso", indicado acima, a IE 3 dá mais opçóes ao estudante para escolher a forma de realizar seus estudos, mas as IES com cursos de graduação praticamente náo consideram essa possibilidade.

- Transferências: a flexibilidade pedagógica supóe liberdade para o aluno transferir de curso, de instituição, de modalidade educacional ou de polo de apoio presencial. Algum tipo de transferência foi observado em todas as instituiçóes de ensino analisadas, mas geralmente ainda é baixa a flexibilidade espacial. Em nossa investigação, não foi possível verificar detalhadamente os tipos de transferências possibilitadas em cada instituição.

- Equivalência de disciplinas e certificação de competências: muitas vezes, o estudante de um curso já realizou atividades/cursos anteriores e a noção de flexibilidade pedagógica sugere aproveitar os seus conhecimentos prévios. Isso é geralmente feito por meio de equivalências de disciplinas, em que o estudante apresenta comprovantes de já ter realizado a mesma disciplina em outra situação; ou pelo processo de certificação de competências, em que os conhecimentos do aluno são avaliados e validados por meio de verificação formalizada pela instituição. Nas instituiçóes investigadas foram observadas as equivalências de disciplinas, mas ainda não implementaram a certificação de competências.

- Atividades (as)sincronas: o horário e o local de realização das atividades constituem um dos princípios mais básicos do processo de flexibilidade pedagógica e as atividades assíncronas viabilizam a liberdade de onde, como e quando estudar. Isso facilita ao aluno organizar sua própria agenda e seu plano de estudos. Em todas as instituições de ensino consideradas na investigação são adotadas atividades assíncronas em articulação com outras atividades síncronas.

Outros pontos referentes ao processo de flexibilidade pedagógica, em termos de espaço, tempo e organização curricular também mereceriam destaque. Os aspectos indicados acima são apenas alguns mais evidentes nas experiências analisadas. No conjunto, fundamentam os elementos que compóem a matriz de 
análise da flexibilidade de um modelo pedagógico, num movimento que vai da educação massificada, marcada pela padronização dos processos, até propostas educacionais mais individualizadas e personalizadas (Figura 3).

\section{Figura 3}

Proposta de matriz analítica para a flexibilidade pedagógica

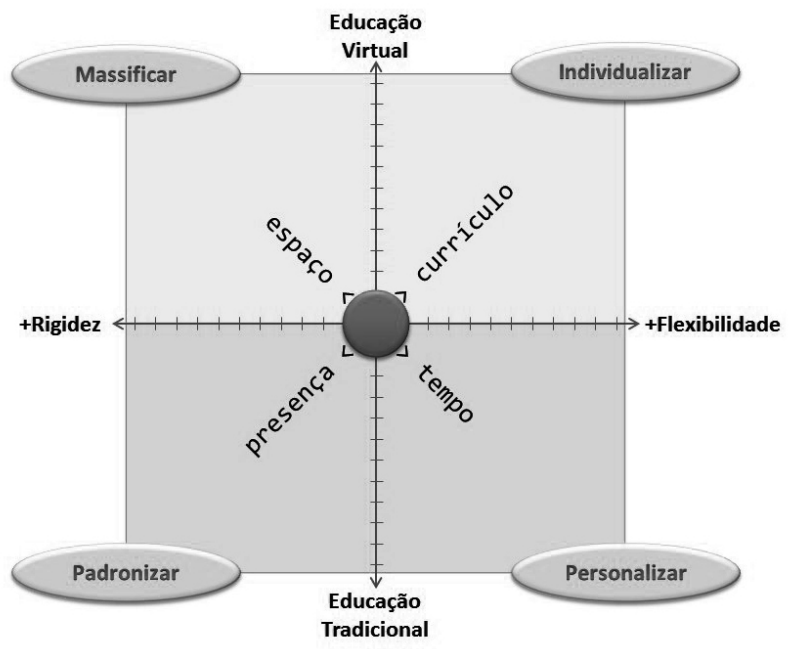

Fontes: Autoria própria.

Pela Figura 3, observa-se que uma proposta pedagógica pode ser mais flexível ou mais rígida, seja em termos de espaço, tempo e currículo. A noção de presença instala-se em conjunto com esses outros três termos e transforma a percepção tradicional de lugares e momentos de ensinar e aprender, além de propor uma revisão da organização curricular da educação presencial. Seja para uma educação mais tradicional ou mais inovadora, há implícito o esforço de educadores para configurar propostas mais personalizadas/ individualizadas e menos padronizadas/massificadas.

Nesse contexto, a configuração de um modelo pedagógico mais maleável em termos de onde (espaço), quando (tempo) e como (organização curricular) ocorre o ensinar e o aprender desperta o desejo de educadores e educandos por estruturas educacionais mais adequadas à nossa época. Esse desejo se realiza no âmbito da cibercultura, que tem exigido e possibilitado propostas de ensino-aprendizagem mais flexíveis e personalizáveis, capazes de atender às particularidades de cada sujeito envolvido e às suas condiçóes de vida, trabalho ou de estudos. Pode- 
mos dizer que tal desejo objetiva-se por meio de iniciativas de educação virtual (seja na $\mathrm{EaD}$ ou na educação presencial com uso intensivo de tecnologias digitais), o que na literatura da área recebe apelidos como educação flexivel, hibrida, virtual, aberta e, no inglês, m-learning, u-learning, b-learning entre outros termos.

Analisando a proposta educacional da Universitad Oberta da Catalunya (UOC - Espanha) ${ }^{5}$, Tubella et al. (2011, p. 3) observam que um dos aspectos que tem marcado as universidades (virtuais ou não) tem sido a busca por um modelo educacional próprio, flexível e dinâmico, completamente baseado na educação virtual. Trata-se de assegurar aos estudantes a aprendizagem de forma semelhante, mas respeitando suas diferenças. Isso agrega valor ao processo e garante habilidades digitais aos alunos, pelo redesenho de espaços, recursos e dinâmicas propícios à aprendizagem. Mais importante ainda, num modelo de educação flexível, as atividades acadêmicas são orientadas para estudantes e para a aprendizagem; ou seja, o foco é a aprendizagem, em vez do ensino.

O esforço de alguns educadores na busca por modelos pedagógicos mais flexíveis e adequados ao perfil de geraçóes mais jovens passa também pela procura por (novas) unidades de medida do ensino-aprendizagem. Por princípio, só é possível tornar algo maleável se o desmancharmos em suas partes constitutivas. De posse das partículas que compóem o todo, cria-se a possibilidade de concebermos e reconstituirmos a totalidade de modo dinâmico e plural. Dialeticamente, a soma das partes não é necessariamente o mesmo "todo" e isso, no âmbito da flexibilidade pedagógica, não é necessariamente um aspecto negativo. Há sempre a possibilidade de constituição de um "novo todo", agregando novos elementos ou rearranjando as suas partículas de modo diferente.

Assim, o conhecimento tem sido dividido, historicamente, em áreas, cursos, disciplinas, módulos, séries, ciclos, semestres, aulas, entre outras noçóes/ subdivisóes. Pedagogicamente, essas partes constituem-se em estratégias para composição de modelos educacionais mais adequados ao perfil do egresso de determinado curso. São estratégias/subdivisôes que possibilitam a maleabilidade da formação, comportada pela (re)organização das partes sob um plano de fundo composto pelos já indicados elementos espaço/lugar, tempo/horários e currículo/ conhecimento.

No âmbito da educação virtual, emergem-se termos/estratégias adjacentes e interessantes. Como exemplos recentes, fala-se muito em objetos de aprendizagem, MOOC (Curso Online Aberto e Massivo, do inglês Massive Open Online Course), unidades de aprendizagem, ciclos de aprendizagem, redundância de conteúdos, certificação de competências, formação personalizada etc. Essas são estratégias que, direta ou indiretamente, buscam flexibilizar pedagogicamente uma proposta educacional. 
Essa discussão, envolvendo estratégias emergentes para organização pedagógica mais dinâmica e outros aspectos da flexibilidade educacional, foi trabalhada também por Mill (2013). Em sua reflexão, o autor traz um mapeamento de produçóes científicas do campo educacional na busca pelo grau de atenção dado à temática em estudos da área. Como resultado, o autor indica que a flexibilidade pedagógica representa um elemento importante para melhoria da qualidade da formação e também é um fértil terreno para pesquisas. Todavia, ainda é um campo carente de estudos e com muitas lacunas de entendimento, considerando que as análises qualiquantitativas denunciam a escassez de publicaçóes voltadas para o melhor entendimento dos diversos aspectos da flexibilidade na EaD.

Os tempos e espaços que caracterizam os contemporâneos adjetivos da educação (presencial ou distância) passam a ser compreendidos como diversidade e riqueza das possibilidades de atendimento a públicos distintos, em condiçóes mais (ou menos) adequadas ou (des)favoráveis. Nesse sentido, a educação virtual seria, portanto, e apenas, uma variação da educação tradicional, para além das distâncias. O importante é que a aprendizagem ocorra.

\section{Considerações finais: a educação híbrida como virtualização do ensino-aprendizagem}

Observamos que as diferenças básicas entre as modalidades de educação presencial e a distância residem, quase que exclusivamente, em aspectos temporais, espaciais e curriculares. As ricas possibilidades de flexibilização desses tempos, espaços e matriz curricular, promovidas pelas tecnologias digitais de informação e comunicação, transformam as formas de relacionamento e de comunicação. A presença de professores e alunos muda sua natureza em função de novos espaço-tempos e de organizações curriculares diferenciadas. Aí está o cerne da flexibilidade pedagógica, que é mais efetiva nesta época marcada pela cibercultura.

Os estudos realizados pelo Grupo de Estudos e Pesquisas sobre Inovação em Educação, Tecnologias e Linguagens (Horizonte-UFSCar), incluindo essa investigação envolvendo experiências de EaD brasileiras e portuguesas, têm demostrado que a virtualização do ensino-aprendizagem é um processo progressivo e pode ser pensado e implementado em escala (Figura 4).

Assim, a análise da flexibilidade pedagógica parte de modelos educacionais mais tradicionais, caracterizados por tempos, espaços e organização curricular mais rígidos e lineares, até modelos pedagógicos mais inovadores e dinâmicos. Geralmente, esses últimos modelos tendem à virtualização dos processos de ensinar e aprender, por meio do uso intensivo de TDIC. Os espaço-tempos virtuais, arraigados na cibercultura, possibilitam formas de organização curricular mais 
flexíveis e abertas, viabilizando uma formação mais personalizada, democrática e individualizada. Nesse contexto, pelo que observamos nas experiências de EaD portuguesas e brasileiras, a dinamicidade dos processos de ensino-aprendizagem está diretamente relacionada aos níveis de virtualização da formação.

\section{Figura 4}

Escala de virtualização do ensino-aprendizagem, com gradação entre a educação presencial e a educação virtual

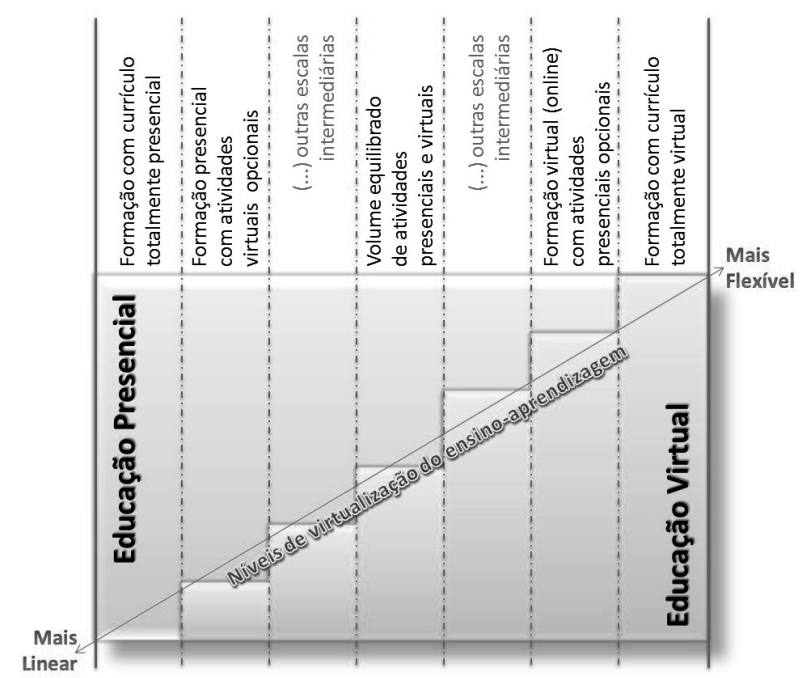

Fontes: Autoria própria, com base em discussöes sobre blended-learning.

Vale ressaltar, todavia, que há vantagens e limitaçóes tanto em processos mais tradicionais/lineares quanto naqueles mais inovadores/dinâmicos ou flexíveis. Por isso, é sensato que o processo de virtualização seja concebido e analisado com cuidado e de modo crítico. Nesse sentido, a educação híbrida (entendida como $b$-learning $)^{6}$ ganha destaque, mostrando-se como uma forma mais adequada de virtualização dos processos de ensino-aprendizagem, ao menos em termos transitórios. Entendemos que a educação híbrida representa, nesse contexto, o fim dos adjetivos (presencial e a distância) da educação como são hoje concebidos. É mais plausível defender uma formação de qualidade, seja ela oferecida presencialmente ou a distância. Como já dissemos em outras oportunidades, o mais importante nesse cenário é valorizar a fusão das riquezas/vantagens de cada modalidade.

No movimento entre a massificação e a personalização da formação, outros termos podem ser considerados relevantes para pensar a flexibilização 
espacial, temporal e curricular, tais como: autonomia do estudante, mobilidade, redundância, estilos de aprendizagem, objetos de aprendizagem, repositórios, unidades de aprendizagem, individualização, transversalidade curricular, produção de materiais/conteúdos just-in-time ou dinamicidade dos conteúdos, valorização de experiências e saberes prévios etc. Esses conceitos merecem análise mais apurada em termos de ensino, aprendizagem, avaliação, metodologia, didática, organização, planejamento, eficiência e objetivos. Embora adjacentes ao foco deste texto, são termos relevantes para análises detalhadas da flexibilidade educacional e, por isso, merecem mais atenção em outros estudos. Fica, portanto, o convite a outros pesquisadores para colaboração nessa empreitada.

\section{Notas}

1. Trabalho resultante de pesquisa financiada pelas agências de fomento Capes e CNPq, às quais agradecemos pelo apoio.

2. O b-learning (blended learning ou educação híbrida), o e-learning (aprendizagem virtual), o $m$ -learning (mobile learning ou educaçáo móvel) e o u-learning (ubiquitous learning ou educação ubíqua) são tipos de configuraçấo da EaD. Saiba mais em Saccol et al. (2011), UOC-INNOVA (2011) ou em <http://pt.wikipedia.org/wiki/Blended_learning >.

3. Atualmente, já são 102 instituiçóes públicas de ensino superior parceiras do Sistema UAB, mas por ocasiáo da pesquisa eram 88 IES com parceria formalizada.

4. Utilizou-se o LimeSurvey® - sistema online gratuito disponível em http://www.ensinolivre. $\mathrm{pt} /$ ?q=node/ 165 .

5. A experiência de EaD da UOC já incorpora diversos elementos da flexibilidade pedagógica. (UOC-INNOVA, 2011)

6. Para saber mais sobre b-learning, consulte Staker et al. (2011).

\section{Referências}

ELIAS, N. Sobre o tempo. Rio de Janeiro: Jorge Zahar, 1998.

FORGRAD. Fórum Nacional de Pró-Reitores de Graduação das Universidades Brasileiras. Concepçôes e Implementação da Flexibilização Curricular. Documento síntese. Campo Grande-MS: FORGRAD, 2003.

FRAGO, A.V.; ESCOLANO, A. Currículo, espaço e subjetividade. Rio de Janeiro: DP\&A 2001.

HARVEY, D. Condição pós-moderna. 18.ed. São Paulo: Loyola. 2009.

HOUAISS, A. Dicionário Eletrônico da Lingua Portuguesa. Rio de janeiro: Editora Objetiva, 2001.

LEVY, P. Cibercultura. São Paulo: Ed.34, 1999. 
MILL, D. Docência virtual: uma visão crítica. Campinas: Papirus, 2012. . Flexibilidade educacional na cibercultura. RIED, 2013 (prelo).

MOORE, M.G.; KEARSLEY, G. Educação a distância. São Paulo: Cengage Learning, 2008 .

ROSSEL, P.; BASSAND, M.; ROY, M. Au-delà du laboratoire. Lausanne: Presses Polytechniques, 1998.

SACCOL, A.; SCHLEMMER, E.; BARBOSA, J. M-learning e u-learning. São Paulo: Pearson, 2011.

SILVA, M.R. Aprendizagem colaborativa, internet e práticas pedagógicas na formação do professor/pedagogo. In: FERREIRA, N.R.; SILVA, M.C. (Org.). Formação docente. Belo Horizonte: Fundac-BH, 2008. p.123-140.

SILVA, T. T. Documentos de identidade. 2. ed., Belo Horizonte: Autêntica, 2004.

STAKER, H. et al. The rise of K-12 blended learning. San Mateo: Innosight Institute, 2011. Disponível em: <http://www.innosightinstitute.org/innosight/wp-content/ uploads/2011/05/The-Rise-of-K-12-Blended-Learning.pdf>.

TUBELLA, I. et al. Flexible education. E-Learning Papers, n.24, p.1-11, 2011. Disponível em: <http://elearningpapers.eu/sites/default/files/media25537.pdf>. Acesso: 9 agosto 2013.

UOC-INNOVA. Evolución y retos de la educación virtual. Barcelona: Editorial UOC, 2011. Disponível em: <http://openaccess.uoc.edu/webapps/o2/bitstream/10609/9781/1/ TRIPA_e-learning_castellano.pdf>. Acesso: 9 de agosto de 2013.

Recebido em 11 de março de 2014.

Aprovado em 24 de outubro de 2014.

DOI: http://dx.doi.org/10.1590/ES0101-73302015122053 